\title{
FETAL ALCOHOL SPECTRUM DISORDERS (FASD) IN THE CONTEXT OF QUALITY OF LIFE OF THE CHILD AND HIS/HER CAREGIVERS
}

\author{
Petra Mitašíková, PhD. ${ }^{1 \star}$, Barbora Vodičková, PhD. ${ }^{2}$ \\ ${ }^{1}$ Dr., Comenius University, Slovakia, petra.mitasikova@gmail.com \\ 2Dr., Comenius University, Slovakia, barbora.vodickova@gmail.com \\ ${ }^{*}$ Corresponding author
}

\begin{abstract}
The present article defines fetal alcohol spectrum disorders (FASD), describes the aetiology, prevalence, manifestations, and consequences of FASD impacting the quality of life of individuals and their families, diagnostic, intervention approaches, and emphasises prevention. Fetal Alcohol Spectrum Disorders (FASD) is an umbrella term covering a group of congenital neurodevelopmental defects and brain damage resulting from prenatal alcohol exposure (PAE). It is a continuum of bio-psycho-social impacts associated with PAE. There are multiple approaches to diagnosing and treating disorders associated with prenatal alcohol exposure during pregnancy worldwide. All persons with FASD have lifelong cognitive, social, and behavioural difficulties. Individuals with FASD present multidimensional challenges in childhood for parents and caregivers, with an impact on other family members. For this reason, families also need support from society. Evidence-based interventions need to be implemented to support individuals with FASD and their families. Addressing this issue requires a multidisciplinary professional approach. FASD is a costly issue for society, so it is reasonable to invest in significant prevention. Our qualitative research mapped the positive and negative influences on the quality of life of child with FASD and his/her caregivers/parents. We found that the negative aspects affecting the quality of life of the child with FASD and his/her caregivers/parents include: Significant manifestations of behavioural problems of the child with FASD in the school and home environment; Early traumatisation and re-traumatisation of the child with FASD; Disrupted relational bond between the caregiver/parent and the child with FASD and Negative impact of parenting a child with FASD on the mental and physical health of the caregiver/parent. We identified the following positive resources supporting the quality of life of the child with FASD and his/her caregivers/parents: Professional support as one aspect of enhancing the quality of life of the child with FASD and his/her caregivers/parents; Compensating for the learning difficulties of the child with FASD in the home environment; Consciously establishing a secure relational bond between the caregiver/parent and the child with FASD; Alternative teaching approaches to the child with FASD in school as a positive influencing factor. The topic of the quality of life of a child with FASD and his/her caregivers/parents is not sufficiently explored in the Slovak and international context. It is about the interconnected links between the child's situation with FASD himself/herself and the impact on his/her whole ecosystem (home environment, parents, siblings, school and broader community). This study presents pilot data on the quality of life of children diagnosed with FASD and their caregivers/parents in Slovakia. The research was supported by a grant Kega No. 002UK-4/2020 Supporting the child with sensory processing disorder through a multisensory environment.
\end{abstract}

Keywords: fetal alcohol spectrum disorders (FASD), prenatal alcohol exposure (PAE), quality of life (QoL) 


\section{INTRODUCTION}

Fetal Alcohol Spectrum Disorders (FASD) is an umbrella term covering a group of congenital neurodevelopmental defects and brain damage resulting from prenatal alcohol exposure (PAE) (Astley, 2004). PAE is the leading preventable cause of children's chronic health and developmental problems (Mattson et al., 2011). The name FASD should not be used as a clinical diagnosis. It is a continuum of biopsycho-social impacts associated with PAE (Astley, 2004; Millians, 2015). The spectrum of FASD includes diagnoses (Center for Substance Abuse Prevention - US, 2014): Fetal Alcohol Syndrome (FAS) (Q86 - this is the most severe diagnosis on the spectrum) (ICD10); partial FAS (pFAS); Alcohol-Related Neurodevelopmental Disorder (ARND); Alcohol-Related Birth Defects (ARBD); Neurobehavioral Disorder associated with PAE (ND-PAE); Static Encephalopathy Alcohol Exposed (SE-AE Static Encephalopathy Alcohol Exposed). The global prevalence of FASD is estimated at 7.7 per 1000 population. The European region has the highest overall prevalence of 19.8 per 1000 inhabitants. The Eastern Mediterranean region has the lowest prevalence of 0.1 per 1000 population. Of the 187 countries in the world, South Africa ranks first (111.1 per 1000), followed by Croatia (53.3 per 1000) and Ireland 47.5 per 1000). The study results indicate that 1 in 13 women who consumed alcohol during pregnancy gave birth to a child with FASD. This finding results in a group of 630,000 babies born with FASD globally each year (Lange et al., 2017). According to the Slovak National Center for Health Information, statistically, between 2011 and 2018, 0.5\% of parents who used alcohol during pregnancy were reported to have child with FASD (e.g., 3.5 cases per 1,000 births in 2018) (National Center for Health Information, 2019). For example, in 2018, when calculated per 1,000 births, there were 3.5 cases of such parents out of a total of 57,059 births in Slovakia. In terms of the age of the parturient, most such births were in the younger age groups. Mothers aged 15-24 years had 4.1 cases per 1000 births. In the older age groups $25-44$, it was an average of 3.3 cases per 1,000 births (National Center for Health Information, 2019). In the Czech Republic, nearly 3,000 babies are born with FASD each year, and of these, approximately 300 suffer from very severe FAS (Stop Alcohol in Pregnancy, 2020). According to the WHO, Slovakia and the Czech Republic generally rank among the countries with higher alcohol consumption than the rest of Europe (Update of the National Action Plan on Alcohol Problems 2013-2020; 2007).

\section{FETAL ALCOHOL SPECTRUM DISORDERS - QUALITY OF LIFE CONTEXTS}

\subsection{Quality of Life of a Child with FASD}

Quality of Life (QoL) is a multidimensional construct that encompasses physical, psychological and social functioning by the WHO definition of health (WHO, 1948). The term HRQOL (Health-Related Quality of Life) is also used in quality of life for individuals with chronic illness (Eiser and Morse, 2001). Based on crosssectional research in Canada on a population of 126 children with FASD (aged 8-21 years), they were found to have significantly impaired HRQOL in the cognitive and emotional domains compared to the healthy population (Stade et al., 2006). All individuals with FASD have lifelong cognitive, social, and behavioural (Vorgias, Berstein, 2020; Riley et al., 2011; Astley, 2004) health and school difficulties (Mattson et al., 2011). School difficulties occur when children with FASD do not receive appropriate intervention support in the context of social inclusion and may also result in suspension, exclusion and even dropout (Millians, 2015). According to Brown and Matter (2020), children with FASD have multiple comorbid diagnoses. They also often meet criteria for, e.g. ADHD, specific learning disorders, conduct disorders, post-traumatic stress disorder, attachment disorders, etc. Findings from 18 studies show that individuals with FASD have a range of disability variations, from somatic problems, high pain tolerance, destructive behaviour, hyperactivity and aggression, to social difficulties with peer contact, school attendance and maintaining stable employment (Domeij et al., 2018). Many children with FASD also experience early deprivation, neglect, abuse, and multiple foster care placements (Millians, 2015). Elbers et al. (2018) studied 80 children with neurodevelopmental dysregulation. Based on their maladaptive responses to stress, it was confirmed that perceived stress affects many functions of the neuroendocrine system, leading to dysregulation of the nervous system (subcortical, hormonal, and autonomic circuits). Early experiences influence neural organisation and behaviour in the same proportion as children's innate characteristics and the environment in which development occurs. Negative experiences interfere with the quality of early experiences and thus with children's skill development. They have a negative impact on children's adaptation to different environments, the acquisition of new skills, as well as on interpersonal functioning and the father-motherchild relationship. Kaščáková et al. (2020) researched the Slovak population $(\mathrm{N}=1018)$ and found that childhood traumatisation may also be related to the development of insecure forms of relational attachment. According to Mihai et al., (2018), children with disabilities are one of the marginalised and excluded groups of children who experience widespread rights violations. However, every person has the right to live freely 
and with dignity on earth, including children with special needs. It is a disability that causes inequality in respect for fundamental human rights. The goal is that all children, including children with special needs, should exercise their fundamental rights as envisaged in the UN Universal Declaration of Human Rights and lead a dignified, physically and mentally healthy and happy life, and achieve an ever-improving quality of life (QoL).

\subsection{Quality of Life of Caregivers/Parents of Children with FASD}

FASD presents a multidimensional challenge for caregivers/parents (Reid and Moritz, 2019). Families feel that a child's difficulties with FASD affect their daily life in a limiting way and make them feel different from others (Domei et al., 2018). Yamaoka et al. (2015) found a significant association with psychological distress in parents and caregivers of children with FASD. Parents of children with FASD report elevated levels of stress (Reid and Moritz, 2019). According to Habalova (2010), this condition requires adaptation to the new situation so that the functions of the family and its mission continue to be fulfilledto its members. A study by $\mathrm{Ha}$ et al. (2011) reports that having a child with a health disadvantage is associated with more somatic symptoms in parents. According to Brehaut et al. (2004), several recent trends in health care highlight the importance of exploring and promoting the health of caregivers and parents of children with health disadvantages. Studies in this area show two main shortcomings. Most conclude from relatively small, potentially biased clinical samples, and most work focuses on the mental health of carers and parents, while little research has been conducted to examine their physical well-being. Clinicians and other health professionals should be aware of the importance of the relationship between a child's health disadvantage and the health of the carers of these children. Research that has looked at the impact of FASD in children on their caregivers and the families in which they live indicates that the areas of quality of life most affected are the family's daily activities and the area of meeting daily needs. Predictors of reduced quality of life for caregivers have been shown to be dependent on the location of housing, the mental health of the caregivers, the gender of the child, and the severity of the child's behavioural problems (Reid and Moritz, 2019). Raina et al. (2005) state that the practical day-to-day needs of the child create complex challenges for parents. The experiences of parents of children with FASD suggest that they see parenting as a lifelong burden and that the whole family feels socially isolated and overwhelmed by the child's difficulties (Domeij et al., 2018). Janušková and Janoško (2021) note that there is a difference in parents' reactions if they had no idea that the child would have health limitations and did not have the opportunity to process this information in advance. Carnevale et al. (2006) cite the theme of families with a disabled child living in isolation. Families reported a profound sense of isolation due to the complex health needs of their children. Families lacked time for respite. Another burden is the lack of social awareness of FASD, which means that parents must constantly advocate for their children in various settings (Reid, 2019). Kotrbová and Majzlanová (2021) give an example of a relieving intervention tool for parents - writing a therapeutic diary. The situation of a family with a child with a disability as Herakova (2010) states, also negatively impacts the partner life of the parents and the life of the child's siblings. Brehaut et al. (2004) state that caring for any child requires significant resources, but when caring for a child with a disability, the demands on these resources often increase. Addressing this issue requires a multidisciplinary approach (Denny et al., 2017).

\subsection{Resilience of a Family with a Child with a Disability}

Family resilience in families with a child with FASD is a construct that describes how families adapt to stress and can cope with the challenging life situation associated with this disability. The higher the resilience in families, the better the quality of the caregiving environment and has a long-term positive impact on the quality of life of individuals with FASD and the entire family (Olson et al., 2009). Widyawati et al. (2020) outline how the concept of parental resilience can be categorised into three distinct but related constructs based on a review of professional studies. The first construct relates to knowledge of child characteristics. It relates to the way parents perceive their child's behaviour. Parents with more excellent knowledge of their child's behaviour are more likely to feel in control of the situation, leading to less parental stress. The second construct is perceived social support from parents. Parents with higher levels of perceived social support report greater emotional well-being and optimism, whereas parents who perceive low levels of support are more likely to experience depression and anxiety. The final dimension of parental resilience relates to positive perceptions of parenting itself, defined as 'joy and happiness in raising a child and acceptance of the parenting role'. Resilience is strengthened if the parent can positively reframe traumatic and stressful events. In qualitative research, Carnevale et al. (2006) found another significant theme for parents of children with disabilities: the search for normality. All families devoted considerable effort to normalising their experiences. They developed a shared routine to make their lives similar to 'normal' families. These efforts appear to have been motivated by an underlying desire for a stable family and home life. This "striving for stability" was 
sometimes undermined by the constraints of family finances, family cohesion, and the unpredictability of the child's condition.

\section{QUALITATIVE RESEARCH}

\subsection{Methodology}

According to Gavora (2005) and Handel (2005), qualitative research provides a space for asking new questions and developing new theories. The individual questions are formed tentatively. They are modified and refined in the course of the research. The researcher collects all the information to clarify the research questions. He makes both inductive and deductive inferences. Thus, data collection and data analysis take place simultaneously. According to the results, the research proceeds further and the individual conclusions are successively examined. According to Gavora et al. (2010) and Handel (2005). Qualitative field data (in our case, data collected from specific caregivers/parents of children with FASD) detail everyday life. They are collected and gathered using a variety of established procedures - research methods. The data collected needs to be accurately described, which is possible in several ways, including verbatim transcription and a summarising protocol. Transcription involves transcribing events into written form. A summary protocol does not preserve the entire text but integrates or omits repetitive parts of meaning. The extracted data is broken down into meaning units - segments. The individual segments are assigned codes and supplemented with interpretive notes by the researchers. The individual meaning units are represented in lower-order categories using numerical codes. The next step is to identify the relationships between the categories. As part of the analysis, an explanation and clarification of the hierarchy of the categories is needed.

\subsection{Research objective}

The research aimed to describe how parents of children with FASD experience their lives, how it affects their lives and how they perceive the quality of life of their children. We were interested in the life story of families with a child with this severe and chronic disability in Slovakia.

\subsection{Research questions}

1. What negative influences and impacts on the quality of life of individual family members are described by caregivers/parents of a child with FASD?

2. What positive and quality of life-enhancing resources do caregivers/parents of a child with FASD communicate?

\subsection{Research set}

The research sample consisted of 7 families (or seven parents). Their selection was deliberate. Inclusion factors were: family with a child with a diagnosed FASD, age of the children from 7 to 18 years.

\subsection{Methods of data collection and processing}

Data collection was conducted through narrative interviews with 7 participants. In multiple sessions, caregivers/parents told the researchers their life stories with their child with FASD.

- The data collected from the interviews were transcribed into written form.

- The transcribed qualitative data was then broken down into separate meaning units. We assigned a numerical code to each unit of meaning.

- The transcripts thus numerically coded were ready for ongoing analysis. Each coded meaning unit was analysed by the researchers. The objectively observed data were interpreted and labelled through margin notes. The notes delineated the content of the research participants' statements and the observed facts.

- Subsequently, we proceeded to categorise the analysed data on an ongoing basis. We sorted this into common second-order categories.

- We then divided the second-order (lower-order) categories into first-order (higher-order) categories.

- Based on the data collected, transcribed, continuously analysed, and interpreted, we formulated four themes related to negative aspects of the quality of life of the child with FASD and his/her caregivers/parents, and four themes describing positive resources supporting the quality of life of the child with FASD and his/her caregivers/parents. 


\subsection{Limits}

A research limitation was the limited number of participants (7 families) out of the 20 interviewed. Only one research method ( narrative interview) was used to collect data. We did not have the opportunity to participant observe and compare the data thus obtained with the real situation in the families.

\subsection{Research results}

In the qualitative research, we formulated four themes related to negative aspects of the quality of life of the child with FASD and his/her caregivers/parents and four themes describing positive resources that support the quality of life of the child with FASD and his/her caregivers/parents. We identified two categories of first (higher) order and 4+4 second (lower) order categories. We list them as follows:

\section{Negative aspects of the quality of life of the child with FASD and his/her caregivers/parents}

1.1 Significant manifestations of behavioural problems of the child with FASD in the school and home environment

1.2 Early traumatisation and re-traumatisation of the child with FASD

1.3 Disrupted relational bond between caregiver/parent and child with FASD

1.4 Negative impact of parenting a child with FASD on the mental and physical health of the caregiver/parent

2. Positive resources supporting the quality of life of the child with FASD and his/her caregivers/parents

2.1 Professional support as one aspect of enhancing the quality of life of the child with FASD and his/her caregivers/parents

\subsection{Compensating for the learning difficulties of the child with FASD in the home environment}

2.3 Consciously establishing a secure relational bond between the caregiver/parent and the child with FASD

2.4 Alternative teaching approaches to the child with FASD in school as a positive influencing factor

We specify the different second-order categories in the following and give examples from the interviews. Each example has a numerical code (the first number denotes the meaning unit and the second the number of the interview).

\section{Negative aspects of the quality of life of the child with FASD and his/her caregivers/parents}

\subsection{Significant manifestations of behavioural problems of the child with FASD in the school and home environment}

This most populous category relates to significant behavioural problems in children in school and home environments. The school and family are unprepared to deal with the child's significant and often nonstandard and unpredictable behavioural manifestations. Problems that are not picked up at an early age manifest themselves outwardly in an exaggerated way when the child enters preschool or school. As a consequence of the domino effect, behavioural problems escalate to extreme manifestations. Behavioural problems in children with FASD always have multiple causes. Adults tend to respond to isolated manifestations, but it is necessary to look at the specific problems in an individual child from multiple perspectives:

a) the physical perspective - the effects of the external physical environment (the influence of physical stimuli - light, noise, smells, pressure);

b) the perspective relating to the body health - e.g. brain damage from PAE, or damage to other organs from PAE - e.g. damaged kidneys, liver, heart...;

c) physiological aspects - e.g. hunger, physical discomfort, sensory hypersensitivity, sleep deprivation;

d) psychological aspects (emotional upsets - anxiety, fear, stress - as consequences of early traumatisation, re-traumatisation and inadequate processing of early traumatic experiences;

e) social aspects (professional deficiency of adults - parents, teachers or other professionals to respond appropriately to problem behaviour).

Examples from the interviews: $20.1 \mathrm{M}$ : "He did not start school until he was seven years and three months old. Moreover, there it had completely blown up!" $23.1 \mathrm{M}$ : "Behaviour problematic, disruptive, takes things 
from other children, cannot wait." 62.1 M: "Too many stimuli exhaust him, he finds it harder to cope with them, and then he explodes from exhaustion... Mato, when he gets distracted in maths, he needs to eat right away, to recharge his energy; otherwise, he explodes and is aggressive." 21.2 M: "At home, the first manifestation was a total lack of mood." 10.2 M: "Playing was destructive, hitting things, toys." $50.3 \mathrm{M}$ : "We only went to the doctor with injuries. He was sticking his arms and legs somewhere; he was unstoppable outside; it was necessary to keep an eye on him all the time." $57.3 \mathrm{M}$ : "The reason was my son's hyperactivity and increased mobility." 119.3 M: "He did not listen until I caught a group of about ten boys in the house; they refused to leave, so we filed a criminal complaint against them." $18.5 \mathrm{M}$ : "The hard part was being around people and in a strange environment." $19.5 \mathrm{M}$ : "Increasingly, he was showing a great deal of distractibility, a poor ability to calm down, to concentrate. In the group of children (in Sunday church school), he was disturbing, sometimes hurtful." 20.5 M: "At the age of 5.5, he started nursery for half a day. Teachers reported that he was disruptive, not concentrating; the children looked at him as the one who was always disrupting and being the "bad boy." 33.5 M: "School, although home school, was a big burden for my son, which manifested itself in the overload on his brain and a severe condition in the child -- amok, attacks on us parents." 19.7 M: "I do not know when exactly the amok behavioural manifestations started when even for an hour or two she was able to scream and both call us to her and immediately send us away. She was kicking and hitting us while doing it. (It was not until around year six that we tried to calm her down because she was hurting herself (banging her head against the wall), others, breaking things, doors)." 30.7 M: "She was dealing more with interactions with the children - disrupting their activities." 32.7 M: "She was rejecting authority, rejecting set boundaries." 33.7 M: "We dealt with difficult, amok, exhausting situations at home that we did not know how to handle well."

\subsection{Early traumatisation and re-traumatisation of the child with FASD}

This category describes the causes of the child's traumatisation and re-traumatisation. From the parents' statements, we learn about the following aetiological links: neglect of the child by the biological parents, staying in different foster environments while the child was placed in the final (foster or adoptive) family, late adoption (after the child is six months old), hospitalisation or too early institutionalisation (nursery/school/preschool) of the child. Among the manifestations related to the above-mentioned causes, parents mentioned: problems with falling asleep; separation from the foster parent when entering a preschool or school institution; child's fear of anything new, difficulties in accepting changes; in social contacts, child's desire to be in control (to control the situation). The child showed signs of post-traumatic stress disorder (e.g. not communicating, not laughing) after placement in the foster family. Gradually, the child overcame the effects of the early stress he or she was forced to experience, which manifested itself, for example, as a problematic and prolonged adaptation to the new family; inadequate reactions to seemingly insignificant stimuli which presended such as screaming, crying, raging, bedwetting; and distrust of strangers.

Examples from interviews: $5.1 \mathrm{M}$ : "We adopted him as a two-year-old. He was in an orphanage until he was two. He went to the orphanage just after a week after he was born." $13.2 \mathrm{M}$ : "Difficulty falling asleep even at home in the evening." 23.2 M: "She did not want to leave me." 25.2 M: "She is afraid of everything new." 26.2 M: "She was afraid to go to school." 33.2 M: "The beginning of school, for about three months, the teacher and I were arguing between the door whether Bibi would go with the teacher or not." 34.2 M: "She refused to leave me; even the assistant did not help." 2.3 M: "He was adopted by my husband and me when he was 16 months old." 44.3 M: "He could not talk or laugh." 17.4 M: "Sept. 2007 (9 months old) placed in an orphanage after hospital admission, placed at parents' request, had nowhere to live, slept outside some nights." 19.4 M: "Around Nov 2007, admitted to hospital for two weeks." 37.4 M: "She reacted inappropriately violent and aggressive to small stimuli (sometimes the stimulus was not obvious to me) - hitting me, my mom, and herself, spitting on us, raging, screaming "nono auntie", throwing herself on the ground (also outside), cowering, not wanting to go any further (like she was stiffening up), not moving away from me, not running after me - and not just at first." 40.4 M: "Profimama told me that she only wet herself at night; she also wet herselfdid notg her afternoon nap." 48.4 M "She didn't trust adults (until now)."51.4 M: "When she was little, she did not want to be picked up by adults; she cried when she was picked up." 52.4 M: "She started kindergarten, from the first day for the whole day, she did not cry, she was good in kindergarten, the teachers praised her." 73.4 M: "Maybe even as a 10-year-old, she was afraid of thieves; in the evening, she asked if the door was locked, she was afraid they would steal her or her toys." 73.4 M: "She liked to visit a lot, but with me, she made a big problem to separate 3.5 from me; she did not want to let me go anywhere, she usually cried." 9.5 M: "The child spent almost the whole first half of her life in the hospital." 1.7 M: "My mother was in the centre for mothers with children since the fifth month of pregnancy."

\subsection{Disrupted relational bond between the caregiver/parent and the child with FASD}


The category portrays the difficulties and challenges of establishing a secure relational bond resulting from the circumstances of unstable relational attachments in the child's early years (e.g., long-term placement in an orphanage). Late child adoption (after the child's 6 th month, when the child's early secure attachment to the parent is missed) is also seen as a negative factor. The neglectful upbringing of the original biological parents and the effects of the long-term toxic stress experienced can also be cited as a further complicating factor. The result is a discontinuity of early experiences of experienced secure attachment (experiences of not meeting the child's basic needs - such as regurgitation for crying, hunger, wetness, for the child's communicative intentions). There were difficulties in establishing secure relational bonds in the foster/adoptive family on the foster/adoptive parents. Often, circumstances (e.g. work) also led foster parents to have to "put" the child in the care of other people or institutions at a time when they should have been working on forming relational bonds with the FASD child and at a time when they should have been fully available to the child. The surrogate parents lacked expertise/knowledge in decoding the real needs of the injured child (problem behaviour is a manifestation of some problem that the child cannot communicate in any other way). Parents looked for the causes of an unstable relational bond with the child, often outside of their relationship with each other. As if the cause of relationship problems was in the child and not in the relationship, in the interaction with the child. The parents did not look for the causes in themselves but in the child. They did not understand that unconstructive relationship building with the child (e.g. miscommunication with the child and decoding of the child's needs by the adult) could also be the cause. There was a lack of consideration of the contextual situations and the child's limited life experiences stemming from his or her traumatic past. There was a lack of consideration of the child's developmental context and medical impairment.

Examples from the interviews: $5.2 \mathrm{M}$ : "Neglected child of homeless, alcoholics by age three." $52.3 \mathrm{M}$ : "After a year of maternity leave, at the insistence of my employer, I started work again, even though this was the most wonderful period of my life with my son." $53.3 \mathrm{M}$ : "For half a year, my son was looked after by my friend, i.e. unemployed, who wanted to repay me for my help to her family in the past." $81.3 \mathrm{M}$ : "I had a demanding job; also business trips, although overnight and within Slovakia, I had to leave him with a carer." 20.4 M: "Placed in a professional family, (approx. two-year-old placed in a professional family)." 84.4 M: "So far she often lies, confabulates, shifts negative things onto me - because of you I hit myself (I am not even near her), you did it etc.., she is sometimes convinced of her lies as truth - she cries when I contradict her." 31.8 M: "Four times change of carer (from profesional mums to me)." $38.4 \mathrm{M}$ : "Certain period since coming into my care where she has hit herself, not cried, not sought my help. Later on, she did." 144.4 M: "In March this year, she was admitted to the children's ward where she expressed that she would not return to my home, that she wanted to go to a children's home." 145.4 M: "She longed to live with her biological mother, who allegedly told her that if she were in the orphanage, she would take her in. So Emma started doing everything she could to get there." $187.4 \mathrm{M}$ : "Emma can be aggressive, and there are times when she tells me she hates me and would rather be in a children's home." 189.4 M: "She has not told me she likes me since she started puberty and started contact with her birth mother - that would probably be a betrayal to her birth mother." 194.4 M: "She has a disrupted relational bond - ambivalent or even disorganised (depending on the perspective of the particular psychologist)." 26.7M: "We were offered play therapy, some play sessions were fine, and some were a source of endless frustration for me." 37.7M: "Again we went through play therapy, the rules laid down and the way of communicating during play irritated my daughter, by my role being more passive there were physical assaults, I was often a shackled prisoner - in hindsight, I can look back on those videos with more forgiveness, but I did not feel comfortable in those games."

\subsection{The negative impact of raising a child with FASD on the parent's mental and physical health}

The given category approaches the issue of the negative impact of the child's difficulties on the parent's health. In our research, parents reported the development of various psychosomatic difficulties related to the undermining of their health, particularly in the area of emotions. Parents' health problems were related to long-term exhaustion and burden in the context of the demanding care of a child with a severe health impairment. Initially, these are subtle indications of future problems (e.g. parents crying, sleep problems, anxiety, emotional upsets, depressive tuning, resignation, apathy, burnout). Parents also reported the negative impacts of raising a child with FASD on their physical health. In addition to the direct impact on parents' health, we also noted statements in participants' accounts regarding the impact on their partner and overall family life.

Examples from the interviews: 49.1 M: "But unfortunately, it broke down again in fourth grade because he got a different teacher. He even tried, but he could not grasp Mato that way. Furthermore, it got to the point that they called us to the school at the end of the fourth grade and told us that after the fourth grade, Mato would have to leave their school because they were a private school, and Mato was disturbing other 
children. And it came to the point again that at the end of the fourth year, they called us to the school and told us that after the fourth grade, Mato would have to leave their school because they are a private school and Mato was disturbing other children. I cried because I wanted to keep him there at all costs (after so many transfers), and I did not even tell him about it the whole holidays. I didn't know how to tell him that they didn't want him here either, and they expelled him." 66.1 M: "And the most important thing is not to talk about the problems all the time, because that stresses not only the child but also us parents, but to build on the positives." M: "Those five years of high school were one drunken horror, which I have already briefly described." 131.1 M: "We didn't get divorced just because we are devout Catholics from the old school and we don't get divorced." 73.5 M: "We did not avoid depression, anxiety." 45.7 M: "Because of the ongoing conflicts at home, our exhaustion, we agreed to medication. She was taking Strattera, now Atofab." $132.3 \mathrm{M}$ : "I have been diagnosed with chronic fatigue syndrome since 2014. When I was issued with a decision to be recognised as severely disabled, the assessing physician stated that I am polymorbid: moderate depression, chronic fatigue syndrome, cancer surgery and treatment, high blood pressure, diabetes." 133.3 M: "My husband is doing a little better; he has severe depression, severe cervical spine damage. It's proven that it is the result of psychological problems."

\section{Positive resources supporting the quality of life of the child with FASD and his/her caregivers/parents}

\subsection{Professional support as one aspect of enhancing the quality of life of the child with FASD and his/her caregivers/parents}

This category indicates seeking the help parents themselves because school institutions have not been very helpful or proactive in this. The issue of FASD itself is not well known among ordinary educators; in Slovakia, it is not well known even among the professional public. Parents mostly approached various civic associations (mostly still the same ones, because only a few of them dedicated to the issue), searched for professional literature themselves, searched for and attended available specialised courses at home and some even abroad. To help their children, some parents have embarked on pioneering work. They set up support groups and civic associations themselves. In the flood of confusing information, many also reached out for scientifically untested sources of help. If a child's problems exceeded a tolerable level, parents sought help from psychologists, psychotherapists, psychiatrists, neurologists, therapeutic educators. Parents also sought help and comfort through faith in God. Parents also tried to communicate with educators at school e.g. on bullying issues. For problems in relational bonding, parents attended, e.g., filial play therapy. Parents failed to find a school for their child with FASD with a pro-inclusive climate. Parents were also taking advantage of parent support groups. They were also turning to specialists for their child's comorbid issues e.g., special educators for diagnoses of learning disabilities. When behavioural problems escalated, parents and their children also underwent psychiatric treatment with medication deployment. According to the parents, skilled, consistent and supportive professional help helped them improve the quality of life of their children and themselves.

Examples from the interviews: $15.1 \mathrm{M}$ : "Experts from the civic association Návrat helped me a lot in this." 24.1 M: "I got my hands on a book by the Polish author Malgorzata Kleck, and it is called Fascinating Children. Moreover, there it dawned on me that Mato probably has FAS." 24.3 M: "I got a little book from her that she bought in a Christian literature shop in Vienna. The author is Paula Sandford from the USA and the title is "New life for you adopted child". My husband translated it and we understood that this was spiritual." matter." 72.3 M: "I ignored them and arranged Educational Psychological Counseling." 108.4 M: "Because of Emma's behavioural problems, I sought help from a clinical psychologist with her at age 5; we did filial therapy. 116.4 M: "I sought help from the Centre for Educational and Psychological Counselling in the second half of my first year because of her learning problems, but they said she had no learning disability, but that she should have had one more year's delay in starting school. Emma had one year of deferred schooling, and one year automatically deferred as she is a December." 122.4 M: "I contacted psychologist from the civic association Return, and at her suggestion, I made an appointment for Emma to be assessed for fetal alcohol syndrome." 138.4 M: "Prior to the FAS assessment, Emma saw by a child psychiatrist. She referred her for genetic testing, which also concluded that she had FAS." 139.4 M: "At the same time, she was referred for an endocrinological examination because of her short stature. 147.4 M: "At the same time, her social worker arranged for her to be admitted to the diagnostic centre." 149.4 M: "The stay in psychiatry helped her revise her ideas, finally she decided to come back to my home. 167.4 Emma was going to art therapy this year, the art therapist ended the cooperation. Emma did cooperate, but not voluntarily; she was not interested in changing anything." 168.4 M: "Since September this year, she has been having consultations with a psychotherapist. Emma is forming a relationship with her; I will be glad if the psychotherapist helps her at least in something." $32.1 \mathrm{M}$ : "The therapeutic educator has helped us, and she 
has kept a protective hand over him."

\subsection{Compensating for the learning difficulties of a child with FASD in the home environment}

For example, parents made self-help aids to helped their children learn and cope with the management of everyday life. Often these were visualisations of procedures of activities (even repetitive ones) that required a series of actions to be performed. These activities' visualisations helped the child navigate through time, sequences of activities, etc. Due to the difficulties in coping with the different subjects at school, it was necessary to pay increased attention to the child in the home environment. Either a parent helped the child with homework or the parents paid for individual tutoring for the child, which lightened their load. Parents described children as lacking independence, reliant on permanent support, accompaniment, and adult assistance.

In most cases, one parent took on the responsibility of tutoring the child (in some families, this role was reversed over time). As long as the homeschooling was systematic, the child did better in school. The parents were more in control of the situation, which positively affected the family atmosphere. Parents were willing to practice and rehearse the child's skills at home according to instructions from different counselling centres. Children showed great difficulties in subjects that required logical thinking and concentration. Families who proceeded to home education wanted to save the child from failing in school due to misunderstanding in the institution of his disability and related circumstances. Families who switched to home education reported a significant increase in the child's quality of life (the child was calm, the curriculum was delivered at home, there was a better opportunity to monitor and regulate the child's workload).

Examples from interviews: 39.1M: "Yes, yes, I made him a manual where he had a visualisation, for example, how to manage the morning ritual, because I was tired of telling him all the time, 'Mato, go brush your teeth, take off your pyjamas, get dressed, have breakfast...' and so he had cards showing the order of these actions that he followed." 54.1 M: "Regarding this private school with a minority language of instruction, the school gave us a condition that Mato would be educated individually (one-on-one) within the school. So I agreed. For the subjects that were not sufficiently staffed for Mato's individual education, we helped to provide tutoring through a private line. That is how we pulled it off this year." 4.3 M: "We have been laughing for years that I was in charge of preschool and elementary school, and my husband was in charge of high school." 76.3 M: "For one whole preschool year, we went to the counselling centre once a month, where, among other things, they gave me materials to practice graphomotor skills." 77.3 M: "Every day after work, I used to spend 20 minutes or more with him like this." $78.3 \mathrm{M}$ : "Towards the end, he lasted 60 minutes; we did not even realise it." 82.3 M: "From the beginning of first grade, I got a first-grade teacher to tutor him, and we had her for two school years." 84.3 M: "The tutor picked my son up at school and came with him to my work in the conference room where they did homework and learned together." 85.3 M: "The first two years benefit on 2." $76.4 \mathrm{M}$ : "She likes repetitive rituals, stereotypes, one kind of yoghurt for breakfast, same wake-up system, same bus service (she attended first and second-grade primary school in a nearby village, small class, smaller group), she did not like to be waited for by someone else in the family by the bus, no big deviation from routine activities, she needs to be prepared for it in advance." $28.5 \mathrm{M}$ : "Most of all, we wanted to help the child learn what she needed to learn and not experience so much rejection from her environment. Homeschooling." 29.5 M: "We knew he was having problems that would not just get worked out in a regular school setting." $31.5 \mathrm{M}$ : "We did not feel like going through many meetings with teachers and their complaints about the child." $32.5 \mathrm{M}$ : "So we took the child's education upon ourselves." 70.5 M: "As a mother, I have been at home with our son since his adoption until now (13 years)." $71.5 \mathrm{M}$ : "I only work a small part-time job as I am daily with his school in the morning and in the afternoon I watch him where he is and what he is doing."

\subsection{Consciously establishing a secure relational bond between the caregiver/parent and the child with FASD}

Given the children's personal histories (e.g., surviving a sequence of foster care placements), parents reported the need to consider the resulting emotional fragility of the children prior to their final placement with a foster family. Mothers attempted to establish secure relational bonds (with more or less success). They also gave time to their children by taking extended maternity leave (in Slovakia, possible until the child starts compulsory schooling). Mothers described the need to respect the gradual process of establishing a relationship with the primary relational person. Children also expressed this need in non-standard ways (e.g. falling asleep together with the parent holding his/her hand, being carried in his/her arms). Mothers reported the positive influence of stereotypes and rituals in the context of living together with the child (e.g., regular bedtime story reading). In upset situations, they recommended giving the child emotional support (not to be seen as the child being disobedient). They reported, e.g., the need to follow the child is inviting of the adult to 
play.

Examples from the interviews: $11.1 \mathrm{M}$ : "I was at home with him for two and a half years - that is, until Martin was 4.5 years old when he started kindergarten." $14.1 \mathrm{M}$ : "I also tried to work on building a relational bond during my maternity leave. 23.4 M: " I started on June 2009, I started contacting her." 24.4 M: "She rejected me. The improvement came when I was dating my niece, then five years old. $30.4 \mathrm{M}$ : "From 01.04.2010 to 31.08.2011, I was on maternity leave with her until she turned 5." 33.4 M: "She used to call me aunty at first, after five months she started calling me by my name, then 'mummy'. 70.4 M: "By age 12, she needed me to lie next to her when she fell asleep, hold my hand, or snuggle up to me." 71.4 M: "At a younger age, she needed to lie on me - she started to do it when she had high fevers, needed much closeness, also when something was bothering her." 74.4 M: "At about half a year after arrival, she started to require frequent carrying in my arms, especially in the morning; we used to prepare breakfast together like this." 75.4 M: "So far, she has been very fond of tickling on the body; she demands it especially after waking up and before falling asleep, she often wanted to cuddle (now less so, on the contrary - sometimes I cannot touch her), even when she was raging in anger, pushing herself on my knees even violently." 90.4 M: "She likes it when I read her books (so far in the evening before bedtime - a stereotype), she prefers stories about children her age, when she was little she also liked poems, now not so much." 192.4 "She tells me many things, we talk mostly before bedtime, she wants me to read to her and tickle her back." 193.4 M: "She comes to me for a cuddle, which in reality usually takes place by lying on my lap, and I can stroke her back." 38.6 M: "Mostly, she just wants to be with me, to have my attention to herself." 45.6 M: "At home, she repeatedly invites us to play." 9.7 M: "I have been trying to wean her since about the third month, taking Domperidone to promote lactation until she was about one year old."

\subsection{Alternative teaching approaches to the child with FASD in school as a positive factor}

New approaches and alternations within teaching methods can positively impact a child's quality of life with implications for improving the family's overall quality of life. Even small changes and adjustments at school make a big difference to peace of mind at home. E.g. not relying on cursive writing for a child with dysgraphia and relying on creative, experiential activities that awake the child's interest and desire to learn are counterbalance to the more non-experiential forms of teaching (e.g. frontal interpretation based on auditory perception). Modifying the school environment favouring eliminating many distractions (e.g. reducing the cluttered environment, maintaining order and system) proved very important. Providing additional tutoring for the child outside the school environment (either by the parents themselves at home or by funding tutoring) proved necessary. It was positive if parents were seen as part of the support team and the school communicated and worked closely with them. Mothers also reported, based on their experiences, how the school should proceed (e.g. accepting the child's fatigue and cognitive limitations, not stigmatising, not pressurising the child's performance and instead identifying and building on the child's positive aspects and talents, creating a calm and non-stressful environment for the child), which from their perspective would greatly help the child and the whole family. Some of the children in our sample attended a Montessori kindergarten or primary school. Parents judged even online learning during the pandemic to be beneficial because of the less stressful demands of school.

Examples from the interviews: 48.1 M: "There in the third grade they did much creating and all sorts of things and Mato liked that a lot and that teacher was able to grab Mato, get to him through his interest and Mato loved that creation. The teacher was very calm; he did not dwell on details, although the classroom, which was not very optimal for Mato, was very overdecorated, overdecorated." 56.1 M: "He took grades 6-7 at medical-educational sanatorium. I came across a great therapeutic pedagogue who was very helpful. At this medical-educational sanatorium, Mato was only allowed to go to school here; he did not have to stay there for the whole week. Moreover, that is where Mato calm down. A child-free, clean, white classroom, high structure, fixed regime, fewer children." 67.1The schools were not run according to the individual child's needs and abilities. He may have had an individual education plan, but I never saw it as a parent! I would also suggest some concessions, e.g. to shorten the length of the school day, because the child is more and more tired faster, which immediately afterwards automatically results in a deterioration of behaviour, which would have prevented it. Acknowledge that he can handle this, and he cannot handle that anymore. For example, in maths, the teacher at medical-educational sanatoriumcould not understand that Mato did not have a foundation on which to build further in maths. One day he learns something, and the next day he does not know what he has learned at all. Just do not grade him - and on the report card, just put passed, not graduated. It would help child considerably. Moreover, conversely, let the child excel at what he is good at. Just listen to the parents. They know best the specifics of their child - what works and what does not. Educate, educate, educate teachers on the issue of FAS." 32.1 M: " He goes to an alternative Montessori program." 36.2 M: "Bibi got used to the teacher and classmates online, and then it got better." 29.6 M: "He 
has been set on a routine since he was a baby; he has been maintaining that routine on his own (especially evening sleep)." 33.6 M: "Individual sports are suitable for him." 39.6 M: "He likes repetitive rituals, a feeling of security, well-being, not too many distractions around." $40.6 \mathrm{M}$ : "He likes a small group." 42. 6 M. "Draws what he sees and experiences around him (does not use colouring books)." $47.6 \mathrm{M}$ : "It requires re-evaluating my demands on him. I can see he is progressing when he has a calm environment when we return to challenging situations later."

\section{CONCLUSION}

The global prevalence of FASD is estimated at 7.7 per 1000 population, but the European region has the highest prevalence (Lange et al., 2017). Specifically, in Slovakia, we record 3.5 cases of parental alcohol use per 1000 births. Detection of cases of children with FASD is at an early stage in the Slovak Republic. In the theoretical overview of the study, we touched upon the issue of fetal alcohol spectrum disorders in the context of the child's and his/her caregivers/parents' quality of life. It is a continuum of biopsychosocial disorders associated with PAE. All individuals with FASD have lifelong cognitive, behavioural, social, and school difficulties and suffer from mono-morbidities (Vorgias, Berstein, 2020; Riley et al., 2011; Astley, 2004; Mattson et al., 2011). In addition to this, many children with FASD show signs of traumatisation. According to Milliams (2015), they experience early deprivation, neglect, abuse and multiple placements in multiple care settings. Families of children with FASD feel that the child's difficulties affect their daily life in a limiting way (Domeij et al., 2018), and Yamaoka et al. (2015) highlight a significant association with psychological distress in parents and carers of children with FASD. Ha et al. (2011) report an association with the onset of somatic symptoms in parents. Similar findings were found in our qualitative research context, which mapped positive and negative influences on the quality of life of individual family members with a child with FASD. We found that the negative aspects affecting the quality of life of the child with FASD and his/her caregivers/parents include: Significant manifestations of behavioural problems in the child with FASD in school and home environments; Early traumatisation and re-traumatisation of the child with FASD; Disrupted relational bond between the caregiver/parent and the child with FASD; and Negative impact of parenting a child with FASD on the caregiver/parent's psychological and physical well-being. We identified the following as positive resources that support the quality of life of the child with FASD and his/her caregivers/parents: Professional help as one of the aspects of improving the quality of life of the child with FASD and his/her caregivers/parents; Compensation for learning problems of the child with FASD in the home environment; Consciously establishing a secure relational bond between the caregiver/parent and the child with FASD; Alternative teaching approaches to the child with FASD in school as a positive factor. The topic of the quality of life of the child with FASD and his/her caregivers/parents is not sufficiently explored in the Slovak and international context. Our research presents the close interconnectedness of the quality of life of a child with FASD with the quality of life of his/her caregivers/parents and the quality of conditions throughout his/her immediate and broader ecosystem - in the home environment, at school, and in the broader community.

This research was financially supported by Kega project No. 002UK-4/2020 Supporting the child with sensory processing disorder through a multisensory environment.

\section{REFERENCE LIST}

Astley, S. J. (2004). Diagnostic Guide for Fetal Alcohol Spectrum Disorders: The 4-Digit Diagnostic Code Third Edition. Center on Human Development and Disability School of Public Health and Community Medicine University of Washington Seattle.

Aktualizácia Národného akčného plánu pre problémy s alkoholom na roky 2013 - 2020. (2007) Bratislava. https://www.uvzsr.sk/docs/info/podpora/Aktualizacia Narodneho akcneho planu pre prob lemy s alkoholom na roky 2013 2020.pdf

Brehaut, J. C., Kohen, D. E., Raina, P., Walter, S.D., Russell, D.J., Swinton, M., O'Donnell, M., Rosenbaum, P. (2004).The health of primary caregivers of children with cerebral palsy: how does it compare with that of other Canadian caregivers? Pediatrics. 114(2),182-91. https://doi: 10.1542/peds.114.2.e182

Brown, J., Mather, M. (2020). Ako byt' rodičom diet'at'a s FASD. Bratislava : Fascinujúce deti, oz. Návrat, oz.

Carnevale, F. A., Alexander, E., Davis, M., Rennick, J., Troini, R. (2006). Daily living with distress and enrichment: the moral experience of families with ventilator-assisted children at home. 
Pediatrics.;117(1), e48-60. https://doi: 10.1542/peds.2005-07894

Center for Substance Abuse Prevention (US). (2014). (Addressing Fetal Alcohol Spectrum Disorders (FASD). Rockville (MD): Substance Abuse and Mental Health Services Administration (US); Treatment Improvement Protocol (TIP) Series, No. 58. Executive Summary. Available

0789. from: https://www.ncbi.nlm.nih.gov/books/NBK344248/

Eiser C., Morse R. (2001). Quality-of-life measures in chronic diseases of childhood. Health Technol Assess, 5(4),1-157. https://doi: 10.3310/hta5040

Elbers J., Jaradeh S., Yeh A. M., Golianu B. (2018). Wired for Threat: Clinical Features of Nervous System Dysregulation in 80 Children. Pediatr Neurol. 2018 Dec; 89:39-48. https://doi: 10.1016/j.pediatrneurol.2018.07.007.

Denny, L., Coles, S., \& Blitz, R. (2017). Fetal Alcohol Syndrome and Fetal Alcohol Spectrum Disorders. American Family Physician, 96(8), 515-522A. https://pubmed.ncbi.nlm.nih.gov/29094891/

Domeij, H. et al. (2018). Experiences of living with fetal alcohol spectrum disorders: a systematic review and synthesis of qualitative data. Developmental Medicine and Child Neurology. (60),8, 741-752. https://onlinelibrary.wiley.com/doi/10.1111/dmcn.13696

Gavora, P. (2006). Sprievodca metodológiou kvalitatívneho výskumu. Bratislava: Regent.

Gavora, P. et al. (2010). Elektronická učebnica pedagogického výskumu [online]. Bratislava : Univerzita Komenského. http://www.emetodologia.feu.uniba.sk/

Ha, J. H., Greenberg, J. S., \& Seltzer, M. M. (2011). Parenting a Child with a Disability: The Role of Social Support for African American Parents. Families in society : the journal of contemporary human services, 92(4), 405-411. https://doi.org/10.1606/1044-3894.4150

Habalová, M. (2010). Zdroje reziliencie rodín detí so znevýhodnením a úlohy včasnej intervencie pri jej posilňovaní. In Horňáková, M. (ed.), Včasná intervencia orientovaná na rodinu. Bratislava: Univerzita Komenského v Bratislave.

Hendl, J. (2005). Kvalitativní výzkum: základní teorie, metody a aplikace. Praha: Portál.

Heráková, K. (2010). Začiatok neobyčajného rodičovstva. In: Horňáková, M. (ed.) Včasná intervencia orientovaná na rodinu. Bratislava : Univerzita Komenského v Bratislave, 2010. s. 62-67.

ICD10. https://icdlist.com/icd-10/Q86.0

Janušková, E., Janoško, P. (2021). Výzvy a prekážky súčasného otcovstva. In Revue liečebnej pedagogiky, 14 (1), 29-39.

Kaščáková, N., Bednaříková H., Dobrotková, A., Petríková, M., Hašto, J., Tavel, P. (2020).Traumatizácia v detstve a zdravie v dospelosti. PSYCHIATRIA-PSYCHOTERAPIA-PSYCHOSOMATIKA, 27 (2), 6 15.

Kotrbová, K., Majzlanová, K. (2021). Therapeutic diary in bibliotherapy. In Problems of education and teaching in the era of digital society. Collection of scientific articles. European Scientific e-Journal, 2 (008), 28-51.

Lange, S., Probst, C., Gme, I. G., Rehm, J., Burd, L., Popova, S. (2017). Global Prevalence of Fetal Alcohol Spectrum Disorder Among Children and Youth: A Systematic Review and Meta-analysis. JAMA Pediatr. 171(10), 948-956. https://doi: 10.1001/jamapediatrics.2017.1919.

Mattson, S. N., Crocker, N., \& Nguyen, T., T. (2011). Fetal alcohol spectrum disorders: neuropsychological and behavioral features. Neuropsychology review, 21(2), 81-101. https://doi.org/10.1007/s11065-0119167.

Mihai, S. I., Mane, K. H., Kachhap, S. (2018). Disability \& quality of life of children with special needs: an interpretative phenomological analysis. European Journal of Special Education Research, [S.I.], nov. 2018. https://dx.doi.org/10.46827/ejse.v0i0.2066.

Millians, M. N. (2015) Educational Needs and Care of Children with FASD. Curr.Dev.Disord.Rep., 2 (sep, 2015), 210-218. https://doi.org/10.1007/s40474-015-0055-5

Olson, H.C., Oti , R., Gelo, J., Beck, S. (2009). "Family matters:" fetal alcohol spectrum disorders and the 
family. Dev Disabil Res Rev. 15(3), 235-49. https://doi: 10.1002/ddrr.65

Poškodenie zdravia konzumáciou alkoholu v Slovenskej republike.

(2019). https://data.nczisk.sk/statisticke vystupy/Poskodenie zdravia konzumaciou alkoholu/Poskod enia zdravia konzumaciou alkoholu v SR 2019 Sprava k publikovanym vystupom.pdf

Raina, P., O'Donnell, M., Rosenbaum, P., Brehaut, J., Walter, S. D., Russell, D., Swinton, M., Zhu, B., Wood, E. (2005). The health and well-being of caregivers of children with cerebral palsy. Pediatrics,115(6), e626-36. https://doi: 10.1542/peds.2004-1689

Reid, N., Moritz, K. M. (2019). Caregiver and family quality of life for children with fetal alcohol spectrum disorder. Research in Developmental Disabilities. Volume 94, November 2019. https:// DOI: $\underline{10.1016 / j . r i d d .2019 .103478}$

Riley, E. P., Infante, M. A., \& Warren, K. R. (2011). Fetal alcohol spectrum disorders: an overview. Neuropsychology review, 21(2), 73-80. https://doi.org/10.1007/s11065-011-9166-x

Stade, B.C., Stevens, B., Ungar, W. J. et al. (2006). Health-related quality of life of Canadian children and youth prenatally exposed to alcohol. Health Qual Life Outcomes 4 (81). https://doi.org/10.1186/14777525-4-81

Stop alkoholu v těhotenství. (2020). Mezinárodní den fetálního alkoholového syndromu. 2. lékařská fakulta Univerzita Karlova, Praha. Vydané 8. 9. 2020.

Vorgias, D., Bernstein, B. (2021). Fetal Alcohol Syndrome In: StatPearls [Internet]. Treasure Island (FL): StatPearls Publishing. https://www.ncbi.nlm.nih.gov/books/NBK448178/

World Health Organization (1948). Constitution of the World Health Organization basic document. Geneva, Switzerland: World Health Organization.

Yamaoka, Y., Tamiya, N., Moriyama, Y., Sandoval Garrido F., A., Sumazaki, R., Noguchi, H. (2015). Mental Health of Parents as Caregivers of Children with Disabilities: Based on Japanese Nationwide Survey. PLoS ONE 10(12), e0145200. https://doi.org/10.1371/journal.pone.0145200

Widyawati, Y., Otten, R., Kleemans,T. \& Scholte,R. H. J. (2020). Parental Resilience and the Quality of Life of Children with Developmental Disabilities in Indonesia, International Journal of Disability, Development and Education, https://DOI: 10.1080/1034912X.2020.1834078 